\author{
Romain Jouffroy \\ Lionel Lamhaut \\ Mihaela Petre Soldan \\ Benoit Vivien \\ Pascal Philippe \\ Kim An \\ Pierre Carli
}

\section{Reply to Mégarbane: is early implementation of extracorporeal life support in severely colchicine-poisoned patients lifesaving? Definitive evidence is still lacking}

Accepted: 1 August 2013

Published online: 14 August 2013

(C) Springer-Verlag Berlin Heidelberg and ESICM 2013

Dear Editor,

We thank Dr. Mégarbane [1] for his interest in our letter [2].

The ingested dose was estimated by the discovery by the patient's wife of an empty bottle of Colchimax $1 \mathrm{mg}$; probably other bottles had been hidden by the patient and were not discovered. Furthermore, the patient first confessed the isolated ingestion of Colchimax to all members of our medical team and then confirmed it to the psychiatric team. He related he did not remember the time and the ingested dose after the coma. Moreover, by virtue of his profession (pharmacist), he well knew the toxic effects of colchicine and the kinetics of these effects.

Colchicine intoxication is marked by a cardiovascular shock classically occurring between day 2 and day 7 as described by Megarbane (http://www. orpha.net/data/patho/FR/fr-colchicine. pdf). In our case, the ECLS could be removed at day 10 , consistent with previous clinical description.

The journal's word limits for correspondence prevented us mentioning the usual prognosticators in colchicine poisoning: prothrombin rate $10 \%$ and leukocytosis $19,100 / \mathrm{mm}^{3}$ at day 2; transient bone marrow suppression: thrombocytopenia $(44,000 /$ $\left.\mathrm{mm}^{3}\right)$ and leucopenia $\left(1,500 / \mathrm{mm}^{3}\right)$ at day 5; and the alopecia that occurred at day 12. As we described, the patient required high doses of catecholamine without achieving a normal hemodynamic profile, for which reason we decided to use ECLS.

Conflicts of interest On behalf of all authors, the corresponding author states that there are no conflicts of interest.

\section{References}

1. Mégarbane B (2013) Is early implementation of extracorporeal life support in severely colchicine-poisoned patients lifesaving? Definitive evidence is still lacking. Intensive Care Med 39:1509-1510. doi:10.1007/s00134-0132975-Z

2. Jouffroy R, Lamhaut L, Petre Soldan M, Vivien B, Philippe P, An K, Carli P (2013) A new approach for early onset cardiogenic shock in acute colchicine overdose: place of early extracorporeal life support (ECLS)? Intensive Care Med 39:1163. doi:10.1007/s00134-013-2911-2

R. Jouffroy $(\bowtie) \cdot$ L. Lamhaut • M. P. Soldan - B. Vivien · P. Philippe K. An · P. Carli

Hôpital Necker Enfants Malades, Anesthésie Réanimation, SAMU, Paris, France

e-mail: romain.jouffroy@nck.aphp.fr 